\title{
On the Proper Role of Coercion in Semantic Typing
}

\author{
James Pustejovsky \\ Pierrette Bouillon $\$$ \\ jamesp@es brandeis.edu \\ pb@divsun.unige.ch \\ †Computer Science Department, Brandeis University, Waltham, MA 02254 USA \\ §ISSCO, University of Geneva, 54 route des Acacias, CII-1227 Geneva, Switzerland
}

\begin{abstract}
In this paper, we discuss the phenomenon of logical polysemy in natural language as addressed by Generative Lexicon Theory. We discuss generally the role of type and sortal coercion operations in the semantics, and specifically the conditions on the application of coercion in aspectual predicates and other contexts We reply to some recent discussion regarding the use of coercion in the grammar, and show that type changing operations are both useful and explanatory mechanisms for capturing linguistic and computational gencralizations.
\end{abstract}

\section{Introduction}

Recently, work in computational semantics and lexical semantics has made an interesting shift. Motivated by a concern for lexical organization and global coherence in the structure of the language lexicon, some researchers have moved towards more expressive semantic descriptions $([16,1,5,10])$, as well as more powerful methods of composition $([22,3])$.

Some, however, have expressed reservations as to the general applicability of type-changing operations such as coercion, as well as the notion of a. generative lexicon itself $([7])$. In this paper, we address these criticisms directly, and show that, upon closer examination of the data, these critiques either miss the point or are not substantiated by the data. Still, without a proper notion of constrajnts on coercion, there can indeed be overgeneration of forms and interpretations in the semantics, and in fact, the notion of conditions on coercion has always been integral to the basic spirit of Generative Lexicon Theory (ct. [19]). The empirical study of the range and limits of type change and cocomposition operations in natural language is an essential part of the research in formal semantics. 'The advantages accompanying generative mechanisus and the chartacterization of languages as polymorphic in well- defined ways far outweight the explanatory inadequacies inherent in traditional approaches to lexical design and semantic projection, what [22] have called word sense enumeration approaches.

\section{Polymorphic Languages and Semantic Expressiveness}

We will assume some general familiarity with the framework of generative lexicon theory, as outlined in $[16,18,1]$. We feel it is important, however, to clarify the motivating principles and general methodology behind such work, since these points seem to be overlooked or misunderstood by some authors ([7]).

In order to help characterize the generative power of natural languages in terms of scmantic expressiveness, it is natural to think in terms of semantic systems with increasing functional power. Furthernore, a natural way of capturing this might be in terms of the type system which the grammar refers to for its interpretation. It has been argued elsewhere $([19,20])$, that there are reasons for describing how semantic systems fall on a hierarchy of increasing expressive power. It seems clear at this point that the current enumerative techniques for lexical description are too impoverished to adequately describe the richness of semantic data, much less to explain either how word senses relate to one another or the creative use of words in novel contexts ([16]).

Briefly, a generative Jexicon can be characterized as a system involving at least the following four lovels of representations: Argument Structure, lvent Structure, Qualia Structure, and Lexical Inheritance Structure. A set of generative devices connects these four levels, providing for the compositional interpretation of words in context. The exact nature of these devices will determine 
the polymorphic expressiveness of the semantics in fairly definite ways. 'l'he best studied illustration of this is the phenomenon of type coetrion, but it is by no means the only onc.

\subsection{Linguistic Evidence for Coercion}

As mentioned in [18], the phenomenon of multiple subcategoriation has motivated much of the type changing literature. The approakh taken in generative lexicon theory builds on the ideas de veloped in [13] and [9], while attempting to derive the syntactic expression of a verb's complement on the basis of a deep semantic 1ypo assignoment, together with syntactic constraints. l'or example, in tho well-studied case of aspectual verb complementation in (1) and (2) below, the verlse begin and commencer carry a doep type selecting tor an event in complement position.

(1) a. John began to mead the book. ( VP $[+-1 N k])$

b. John began rading the book. (Gip)

c. John began the book. (NP)

(2) a. Jean a commencé à lire le livere.

b. Jean a commencé lo livere.

This aleep type is able to project to one of three possible surface forms, depending on which coer cion rule applies ([18]). There is, however, only one semantic type being selected fol, and the clustering of the particular syntactic forms alppearing as sufface complement lypes in (1) are systematically projected by virtue of this sematotic type. 'That is, any verb, like begin, selecting for an "unsaturated event", will paradigmatically allow for the expression of the three grammati cal forms shown above, assuming surface syntactic constraints are satisfied. For this reasom, the structuring of this kind of knowledge, where this event type has syntactic expression as any one of the surface types in (1), is called a leated ronceptual paradiym (lep). In this view, the NP, a book, is coerced to the appropriate type reculued by its governing verb. What makes coercion possible in this case is the availability of the required typo, given as part of the NP's qualia structure, indicating, for example, that the rewe lobe for book is the activity of realing, while the AGLN'Tus: role is the act of writing. The result of apply ing this coercion operato to an N' is eflectively to create an extension of the NP' neaning, called a metonymir reconstrution. In the case of the NP, a book, for cxample, the operator produces Insaturated event clenotations.

There are several phenomena discussed in Go

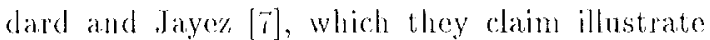
that coercion is not a viable interpretive strategy for linguistic semantics. Although none of these apparent counterexamples is in fact a problem for Gencrative fexicon 'lheory, it is important to dis. cuss each briefly to show why they are false problems. We will concentrate, however, on the selectional properties of aspectual verbs such as commeneer and begin, in order to show very clearly that sense enumerative approaches such as Gofard and Jayce's are nissing the point of linguistic and computational generalizations, as regards to how the lexicon contributes to the compositional semantics.

The first apparent counterexamples, discussed in Codard and bayez ([7]), to the general ap)plication of type changing operations show that commence does not universally allow NP' coml. plenents with a coerced interpretation. For example, the NP's in (3) bolow do not have the expected event readings that one woukl predict, were there no constraints on the application of type cooreion operations.

(3) a. * Jean a commencé une symphomie ([7]). "John began [to listen to] a symphony". b. *Marice a commencé l'auloroute. "Mary began [to drive on] the highway." c. ${ }^{*}$ John began the dictionary $([16\})$.

"Wohn began [to consult/roference] the dictionary."

But, as already pointed out in [?], the acceptability of coercion with aspectual predicates such as commencer and begin is conditioned by the telicity of the event taken as its complement. Briefly, these verlos select for an event of the sort ' $\mathrm{I} R \mathrm{~N}$. SrToN, ruling out the cocred interpretations of listen to for (3a), drive on for (3b), and consull for (3c), which are all prochss events. Furthermore, constraints due to "bonndedness" of the predicate ((4a) vs. (4b)) are enticely consistent with conditions on coercion in Genorative lexicon Theory (cf. $[16,17])$.

(4) a. Joan a commence le fromage/ le livee. "John began the cheese (eating) / the book 
(reading).

b. *Jean a commoncé du fromage / des livres.

"John began cheese (cating) / books (reading).

Namely, the homomorphic relation between the NP type (mass vs. count) gives rise to process and transition interpretations of event structures (corresponding roughly to the amorphous and bounded reading's respectively, of Codard and Jayez's analysis).

If it is truly an explanatory and productive operation, coercion should be not just a property of object phrases, but affect the semantic inter. pretation of subjects and other positions as well (cf. [17]). For example, the interpretation of psychological predicates such as in (5) involves a metonymic reconstruction of the subject as an experiencing event.

(5) a. Books bore me.

b. 'The movie frightened Mary.

c. Mary's face / her chatter / listening to Mary bores me (cf. [7]).

Contrary to Godard and Jayez's claim, all of the above examples indicate very clearly a subject event reading; i.e., reading books, walching the movie, secing Mary's face, and listening to her chatter, as argued in [16]. With examples such as *The book began last week, however, coercion is not possible for rather trivial reasons; namely, as a violation of control. It is, by the way, not surprising to find asymmetries between argument positions. Anaphora, control, and extraction from subject position all behave differently from argument positions within VP. The point is that linguistic evidence supports an 111 derlying semantic type, directly explaining what the connection between the subject and object of the experiencing relation is. In [17], the underlying semantics of psychological predicates such as bore, anger, and frighten is a causative structure where the surface subject is the logical object of an experiencing relation. For example, the event structure for the verb anger has the following form:

$\left[\operatorname{Exp}\left(e_{1}, x, y\right) \wedge \neg P\left(e_{1}, y\right) \wedge \operatorname{angry}\left(e_{2}, y\right) \wedge\right.$ $\left.\neg e_{2} \prec e_{1}\right]>\operatorname{cause}\left(\epsilon_{1}, e_{2}\right)$

The qualia structure projected by the NP contributes relational information as to just what manner of experiencing is involved. Short of general world knowledge, how are we to infer the particular manner in which Mary became bored in (4b)? By knowing what a movie is, we know how to use it and experience it; this is the defining role of the qualia structure. And yet, to claim that the qualia are a useful representation (which Godard and Jayez adinit), without exploiting them through type reconstruction operations (e.g. co(rcion), is to fail to see the logical relations betweon lexical senses and derived senses in the language. It is as though we were to permit traces in our grammatical formalism without having a statement of binding, or otherwise knowing what to do with them.

The third argument against coercive operations involves examples such as a long novel and a brighe bulb. These are to be contrasted with a red book and an opaque bulb. As pointed out in [21], the adjectives here modify a distinguished event predicate (i.e. a quale) associated with the head, read for book, and illuminate for bulb. Godard and Jayez scem to think that because the NP can appoar in an environment typed for an individual, such as (6) below,

(6) Jean a acheté un long roman.

"John bought a long novel."

that this is a counteroxample to type coercion. But this surely misinterprets what role the adjective is playing in the semantics. As already argued very explicitly in [22], the modification by an adjective such as long, rapide (fast), or brillant (bright), is a submodification on the appropriate qualia of the head.

(7) $\lambda x[\operatorname{roman}(x) \ldots \wedge$

$$
\left[\operatorname{Telicc}(x)=\lambda w \lambda e^{T}\left[\operatorname{lire}\left(e^{T}, w, x\right) \wedge\right.\right.
$$$$
\left.\left.\left.\operatorname{long}\left(e^{T}\right)\right]\right]\right]
$$

The resulting compositional structure is still the type of the whole NP, and has no effect whatsoever on selection by an outside governor such as acheter (buy) as in (6).

The final significant argument Godard and Jayez present against coercion operations involves the apparent lexically idiosyncratic nature of cocrcion. Why should commenecr and finir allow coercion while cesser and arrêter do not? There is no space to detail the distinction here, 
but it is apparent that this is duc to a somantic type distinction between these classes of prodicates.

In what follows, we demonstrate how the apparent violations of the concive behavior of begin-predicates actually reveal a much deeper semantic distinction between two logically related senses of the verb, in all the complement forms they take, and not just NP complement cases. This can be applied mutatis mutandis to commencer.

\section{The Semantics of begin}

As argued in Section 2 albove, the well-formedness of object complement coercion with aspectual predicates such as begin is conditioned by the event sort of the qualia associated with the NP itsolf. 'Thus, only NPs having associated transition events will allow coercion and control. 'This is not to say, however, that begin selects only lor transition events. There are, of conse, perfectly grammatical examples of process complements, as shown in (8) bolow:

(8) a. The snow began to fall at midnight.

b. John began to feel ill.

c. The war began to reach into Bosnia.

These examples illustrate the use of beyin as a raising verb. We will follow Perlnutter [14], in distinguishing between two senses of the verb begin, distinguishable not by the selectional properties given in Godard and Jayez, but rather, conforming to the distinction that [1.1] made; namely, as either a Raising or a Conlrol verb.

The analysis is as follows. 'There are indeed two grammatical expressions of the verb begin, as Raising and Subject-Control forms: As a control verb, the event sort specified as the complenent is a'rRANSITION. As a Raising verb, however, the event may be any sort. 'This follows the typing assignmentis below:

Control: $\left(r-\cdots, c^{l}\right) \rightarrow\left(r-c^{l}\right)$ Raising: $\left(c^{a} \rightarrow c^{T}\right)$

The examples above and in (9a) and (9b) below illustrate the raising interpretation of begin:

(9) a. The acid began to corrode the marble. b. It began to rain.
We will assume that raising is accomplished by function composition, in the manner of [8]. 'The manner in which Raising is treated as function composition (FC) is as follows: begin is $\epsilon^{\sigma} \rightarrow \epsilon^{T}$, to corrode the marble in the example above is $e \rightarrow c^{\prime}$. Then, $F^{\prime} C($ begin, $V P)=$ $\lambda \mathcal{P}[$ begin' (corrode $\mathcal{P}$, the-marble)].

$\Lambda$ s pointed out in [?], VI' ellipsis can be used as a diagnostic for determining whether a complement is part of a raising or control construction. Some predicates permit both a control and noncontrol reading, such as (10) below, where John tray be intentionally dioting or he may be ill.

(10) John began to lose weight.

Notice however, that in Linglish the sentence in (11) has only the intentional inchoative reading, and not the raising version.

(11) John began to lose weight, and Mary began too.

What this indicates is that there are indeed two constructions at play here, as teased apart by cenhain diangostics. Finther evidence comes from imperalive structures (12) and fore-complement constructions, which require the control sense of the verb.

(12) a. * Begin looking for a job, you lousy bum! b. Start looking for a job, you lousy bum!

These data indicate that begin, in the control incopretation, strongly prefer's a telic (transition) event complenent.

We have argued that there are two sellses of the vert brgin, corresponding to raising and control predicates. 'These senses, however, are not arbitrary types but are logically related to one another in the same way that the different senses of unaccusative/causative verbs, such as break, and sink are related. In [23] it is shown that verbs such as sink and affondare are logically polyse. mous in predictable ways, and don't need to be assigned multiple lexical ontries. The same gencralization holds for verb such as begin: begin is the lexical version of at unaccusative marker, but for propositions rather than for entities.

In [22] and [23], a general mechanism is defined which makes the appropriate type available for a coercion operation. As discussed in [16], 




Figure 1: Type Inference of (13a).

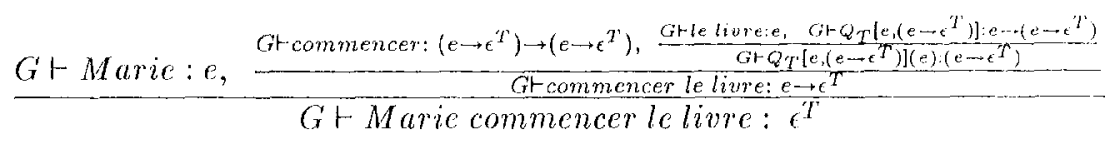

Figure 2: Type Inference of (13b).

the qualia can be seen as partial functions, returning the value of a particular quale for an NP. The combined set of qualia provide a sot of type aliases for the expression containing thom (cf. [18]). One particular mechanism, type pumping, has been explored as a means to gencrating the alias set $([20])$.

I et $G$ be the typing judgements with respect to a grammar. Then, by convention, $G \vdash \alpha: \tau$ represents a type assignment of $\tau$ to the expression $\alpha .{ }^{1}$ Thus for example, the type available to an expression $\alpha$ with quale $Q_{i}$ of type $\tau$, can be seen as the following type inference: ${ }^{2}$

$$
\frac{G \vdash \alpha: \sigma, \quad G \vdash Q_{i}[\sigma, \tau]: \sigma \rightarrow \tau}{G \vdash Q_{i}[\sigma, \tau](\alpha): \tau}
$$

This says that, given an expression $a$ of type $\sigma$, there is a coercion possible between $\sigma$ and $\tau$, which changes the type of $\alpha$ in this composition, from $\sigma$ to $\tau$. We will illustrate the further application of this coercion operation below, as used in the begin examples. In (13a), we see how the aspectual verb commencer selects the complement $\mathrm{VP}$, and how in (13b), an NP is coecced into an event interpretation.

(13) a. Marie a commencé à lire le livre. (vP)

b. Marie a commencé le livre. (NP)

Following [20], we can view the basic composition of the sentence in (13a) as type inference in rigure 1.

\footnotetext{
${ }^{1}$ See [6] for explanation of formal mechanisms of type inference within the $\lambda$-calculus, and $[10,2]$, and $[22,19]$ for its application to lexical representation.

${ }^{2} \mathrm{Sec}[20]$ for details of coercion as type inference.
}

For the derivation of ( 136$)$, coercion applies to the complement $\mathrm{NP}$, resulting in the appropriate type selected by the verb, as illustrated below in Figure $2 .^{3}$

In the case of bogin with NP' complements such as the symphony or the motorway, the coercion is not possible, given the type mismatch in the intended qualia relation (i.e. listening and driving are procrss events). Notice, however, since the AGENTIVE for each has an event of sort TRANSITION, these are possible coercive interpretations; i.e. perform the symphony, or build the highuay.

Notice that one might expect there to be raising constructions involving coceded $\mathrm{Nl}^{3}$ comploments. But these do not exist, as the ungrammaticality of *John began his nap (non-control reading) illustrates. 'This is due to the lact that coercion is governed by the type of the controller, in this case of type $e^{\sigma} \rightarrow \epsilon^{T}$. This coeccion will be successful if such a type exists in the alias set of the complement. Since function composition is an operation at the level of the VP, there is no point in the derivation such that the appropriate type is available for the rule to apply.

As a final observation, it should be obvious now why verlos such as enjoy allow a much broader range of complement coercions (cl. [16] for details). They are typed for taking an event of any sort, thereby allowing the process events of the 'rEHA roles in enjoy the symphony / the movie.

\footnotetext{
${ }^{3}$ We ignore for now the type distinction between individuals, e, and generalized quantifiers, $\langle\langle e, t\rangle, t\rangle$. In the full version of the paper, we show the type shift taking this distinction into acconnt.
} 


\section{Conclusion}

We have attempted to respond to specific criticisms regarding coercion operations in the semantic interpretation of uatural languages. The problems pointed ont by Codard and Jayez do illustrate that conditions on coetcion are a necessary part of the semantics, but as we demonstrated, these are alroady an integral component of Generative lexicon Theory. In the process of this discussion, we have reiterated the advantages of a generative lexicon in the context of the larger theoretical and methodological issues. More specifically, we showed how begin and commeneer exhibit both rasing and control behavior, and that this is an instance of the lasger alterna. tion class between causative and inchoative verbs, itself an example of logical polysemy.

\section{References}

[1] Copestake, A. and W. Briscoe, "Iexical Operations in a Unification-Based Franework," in J. P'ustejoysky and S. Bergler (Fids.) Lerical Semantics and Knowledge Representation, Springer Verlag, Now York, 1992.

[2] Copestake, Ann, "Defaults in the LK'B", in 'T" Briscon and $A$. Copestalio (Eds.) Dofaull Inheritance in the Lexicon, Cambridge University Press, 1993

[3] Dölling, Johannes, "llexible Interpretationen durch Sortenverschiebung", in Ilse Zimmermann, Anatoli Strigen (eds.) Füqungspotenzen, Berlin, Akademie Verlag, 1992.

[4] Dowty, l)avid R., "On Some Recent Analyses of Control," Linguistics and Philosophy 8, pl. 1-41, 1985

[5] Gerstl, Peter, Die Berechnung non Worlbedentung in Sprachverabeitungsprozessen. Ph.D. 'Jhesis, Universität Hanburg, Fachlerech lnformatik, 1993 .

[6] Gunter, Carl, Semanlics of Programming Languages, MTI Press, Cambridge, 1992.

[7] 1). Codlard and J. Jayes, "lowards a proper treatment of Coercion Plesnonena", in Procediny of the 1993 European $A C L, 1993$

[8] Jacobson, P. "Raising as l'unction Composition", Jinguistics and Philosophy, 13:123-476, 1950).

[9] Klein, li. and 1. Sag, "lype-1)riven Transtation", Linguistics and Philosophy, 8, 16:3-202, 1985.

[10] Morrill, Glyn, Type-Logical Grammar, Onderzoeksinstituut voor Tat on Spmak, Utrecht, 1992.
[11] Nunberg, (: "Ihe Non-uniqueness of Semantic Solutions: Polyseny", Cinguistics and Philosophy $3: 143 \cdot 184,1979$.

[12] Partes, Barlara, "Syntactic Categories and So mantic Type", in M. Rosner and R. Johnson (Fds.) Computational linguistics and Fornal Semantics, Cambridge University P'pess, 1992.

[13] Partee, 13, and M. Rooth. "Generalized Conjunclion and Type Anbiguity", in Meaning, Use, and Interprelation of Language, Bänerle, Schwarze, and von Stechow (eds). Walter de (rruyter, 1983.

[14] Perlmuticer, David, Deep and Surface Structure Constraints in Syntax, IIolt, Rinchart, and Winston, New York, 1971.

[15] C. Pollard and I. Sig, Information-Based Syntax: and somantics (SLI lecture Notes Number 13, Stimford CA (1987).

[16] Pustejovsky, Janes, "l'he Gemenative Lexicon", Computational Linguistics, 17.4, 1991.

[17] Pustejovsky, James, "Ilıe Syntiax of Fveut, Struc ture", Cognition, 41:17-81, 1991.

[18] Pustejovsky, Janes, "Iype Coercion and Lexial Selection". In .J. Pustejovsky (ed.), Semantics and the lenicun, Khuver Acalemic Publishers, Dor drecht, 1993.

[19] Pustejovsky, Jinnes, "Ihinguistic Constraints on Type Coercion". In P'. Saint-Dizies and b. Vicgas (eds.), Computational Lexical Semantics, Cannbridge Iniversity P'ress, 1994.

[20] Pustejovsky, Jannes, "Sonantic 'Typing and Degrees of l'olynorphism", in Martin-Vide Current lssues in Malhemalical Linguistics, Elsevier, Hol. land, 1994

[21] P'ustejovsky, James and Poter Anick, "On the Semantic Interpretation of Nominals", in Procedings of toll International Conference on Compalational Lingutistics, Butapest, Hungary (1988) 518 523 .

[22] Pustejovsliy, James and Bran Boguraev, "hexical Knowledge Representation and Natumal Lau guage Processing", Arlificial Intelligenee, 63:193$223,1993$.

[23] l'ustojovsky, James and Federica Busa, "Derived Unacensativity and the Compositionality of Went Structure", submited to Natural Language and linguistic Theory.

[24] Sag, 1. ancl (. Pollard, "An Integrated 'lheory of Complement Control", Language, 67:1, 63-113, 1991. 